\title{
Inequality of Health Spending and Public Health Outcome in Countries of the WHO's Eastern Mediterranean Regional Office (EMRO)
}

\author{
Ali Mohammad Ahmadi ${ }^{1,2}$, Abbas Assari-Arani ${ }^{1,2}$, Mohammad Meskarpour-Amiri ${ }^{3,4, *}$ \\ ${ }^{1}$ Economic Research Institute, Tarbiat Modares University, Tehran, Iran \\ ${ }^{2}$ Faculty of Management and Economics, Tarbiat Modares University, Tehran, Iran \\ ${ }^{3}$ Health Economics Department, Health Management Research Center, Baqiyatallah University of Medical sciences, Tehran, Iran \\ ${ }^{4}$ Health Economics Department, Faculty of Management and Economics, Tarbiat Modares University, Tehran, Iran
}

*Corresponding Author: Mohammad Meskarpour-Amiri, Ph.D. Candidate in Health Economics, Health Management Research Center, Baqiyatallah University of Medical sciences, Tehran, Iran. Email: mailer.amiri@gmail.com

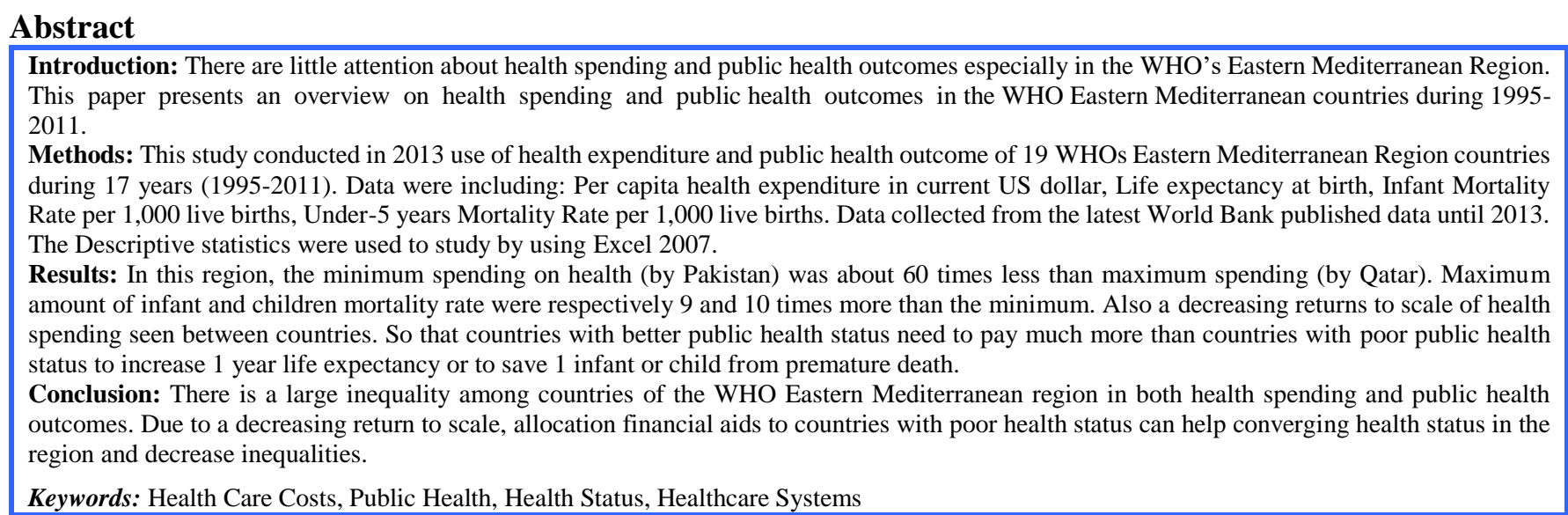

Article History: Received: 11 May. 2015; Accepted: 9 Jul. 2015; Online Published: 26 Nov. 2015

Cite this article as: Mohammad Ahmadi A, Assari-Arani A, Meskarpour-Amiri M. Inequality of health spending and public health outcome in countries of the WHO's Eastern Mediterranean Regional Office (EMRO). Int J Travel Med Glob Health. 2015;3(4):137-41.

\section{Introduction}

A significant increase in health care spending without any significant improvement in health outcomes is one of the most controversial health challenges during past decades. It's the aim of every health care system and policymakers to improve public health outcomes (such as mothers and child health, life expectancy, etc.) in a certain level of cost [1]. As a result of the global commitment to the Millennium Development Goals (MDGs), the world experienced a significant improvement in all health outcomes and World Health Organization Eastern Mediterranean Region (EMR) countries were not an exception. Life expectancy at birth -as the most common measure of population's health- has continued to increase remarkably in EMR countries over the past few decades, reflecting sharp reductions in mortality rates at all ages. Also, a significant improvement experienced in mothers and child health indicators (such as maternal, infant and under five-year child mortality rates) in the region $[2,3]$. These gains can be attributed to a number of factors, including better education, nutrition, sanitation, housing as well as greater access to health services $[4,5]$. Several studies have confirmed that there is a positive relationship between life expectancy at birth and health expenditure per capita worldwide [6-8]. A recent study by Joumard [9] in 2010 showed that an increase of total health spending is the possible reason for at least $40 \%$ of improvements in life expectancy since 1990. So, this fact should be considered that health spending is necessary for analyzing any public health achievements cross-countries.
Total health spending is the aggregation of public and private health expenditures, paid to buy any health related goods or services during a certain period of time (usually a year). The public health spending is any health spending financed through government general budget, taxation system or external sources, including grants and loans. While, the private health spending financed through private health insurance premiums and out of pocket (OOP) payments [10]. An assessment of global health expenditures patterns by Poullier[11]showed that spending on health -as share of income- are significantly greater for high income countries. Also, the range of spending on health -as percentage of GDP- is different from $1.5 \%$ to $13 \%$ among various countries. This is while the world's highest shares of populations living in Asian, African, the United State and the European countries spending on health is relatively too much higher.

Health systems in EMR countries are facing new challenges of change in disease patterns, demographic and socio-economic features of general population, along with rising health costs. In such situations, a comprehensive review of health spending and public health achievements can be helpful for policymakers to identifying and overcoming some important health care systems challenges such as inequalities, inefficiencies and weaknesses [12,13]. For example it seems that some health systems, especially lower income countries, fail to provide the essential services while some health systems, especially high income countries, are facing inefficacy in provision of health 
services [8, 14, 15]. Although adequate and sustainable financing can help heath system progress toward MDGs, but the final outcome of any health system largely depends on other multiple variables like health system policies, efficiency, cultural and political considerations and et al. [2, 16].

While the increasing rate of health care cost has been subject of too many studies, there are still little attention about health spending and public health outcomes especially in EMR countries. Comparison of health spending and public health outcomes across countries and over time can provide important insights into policies that improve health system performance and outcomes. This will be achieved through providing easily and clearly comparison of health systems efficiency to gain public health outcomes, development partnerships and share knowledge across the region, draws lessons from success and failures and that can assist policy makers in the formulation of strategies and brings recommendations to policy makers $[17,18]$.

This paper presents a cross-country comparison on health spending and public health outcomes in countries affiliated to the World Health Organization Eastern Mediterranean Regional Office (EMRO) during 17 years, to provide important insights into policies that improve health system performance and outcomes in this region.

\section{Methods}

The present study was conducted in 2013. During a 17 years (1995-2011) time series data including health spending and public health outcomes of all 22 EMRO countries were used in the study. Data included: Per capita health expenditure in current US dollar, Life Expectancy at birth (LE), Infant Mortality Rate per 1,000 live births (IMR), Under-5 years Mortality Rate per 1,000 live births (Under 5 MR). The data were collected from the latest World Bank published data until 2013. However, due to lack of complete and reliable data, four countries were excluded from study including Somalia, South Sudan, Palestine and Afghanistan. Descriptive statistics were used to study the spending on health and public health outcomes by using Excell2007 software.

According to the World Bank definition; per capita health expenditure indicates the sum of public and private health expenditures as a ratio of total population (measured by current U.S dollar). Also, Life Expectancy at birth (LE) defined as the number of years an infant would live if the patterns of mortality stay the same. In this study, the average amount of per capita health spending and Life Expectancy (LE) during 1995-2011 was analyzed. Also, per capita dollar paid to achieve 1 Year LE defined as "the average per capita health expenditure paid by each country" divided by "the average LE achieved by that country".

According to the World Health Organization definition; Infant Mortality Rate (IMR) defined as the number of infants (0-12 month old) dying per 1,000 live births in a given year. So in our study, the number of infants saved from premature death is defined as 1000 minus IMR. Also, the per capita dollar paid to save 1 infant from premature death defined as "the average per capita health expenditure paid by each country" divided by "the average number of infants saved from premature death at that country". Also under-five year child mortality rate (Under $5 \mathrm{MR}$ ) is defined as the probability that a newborn will die before reaching the age five per 1,000 children in the current age-specific mortality rates. So, the number of children saved from premature death is defined as the 1000 minus under-5 MR. Also, per capita dollar paid to save 1 child from premature death defined as "the average per capita health expenditure paid by each country" divided by "the average number of children saved from premature death at that country".

\section{Results}

Table 1 showed the average health spending and public health outcomes in EMR countries during 1995-2011. On average, Pakistan and Qatar have minimum and maximum per capita spending on health by 19.6 and 1161.1 per capita US dollars respectively. The minimum spending on health (by Pakistan) was 59 times less than maximum spending (by Qatar). Also, on average, the minimum and maximum life expectancy was 58 and 77.2 years respectively in Djibouti and Qatar. The minimum and maximum Infant Mortality Rate was 9 and 83.1 respectively in Emirates and Pakistan. So the infant mortality rate in Pakistan was 9 times more than Emirate. Also, the minimum and maximum under-5 year child mortality rate was 10.05 and 105.7 respectively in Emirates and Pakistan and the under-5 year child mortality rate in Pakistan was about 10 times more than Emirate.

Table 1. Average health spending and public health outcomes in EMR countries during 1995-2011

\begin{tabular}{|c|c|c|c|c|}
\hline \multirow[b]{2}{*}{ Country } & \multirow{2}{*}{$\begin{array}{c}\text { Spending on Health } \\
\begin{array}{c}\text { Per capita health } \\
\text { expenditure (US \$) }\end{array}\end{array}$} & \multicolumn{3}{|c|}{ Public Health Outcomes } \\
\hline & & $\begin{array}{c}\text { Life expectancy at birth } \\
\text { (years) }\end{array}$ & $\begin{array}{c}\text { Infant mortality rate per } 1,000 \\
\text { Live births }\end{array}$ & $\begin{array}{c}\text { Under-5 years mortality rate per } \\
1,000 \text { live births }\end{array}$ \\
\hline Bahrain & 616.9 & 75.1 & 10.7 & 12.4 \\
\hline Djibouti & 58.5 & 58.0 & 79.9 & 101.1 \\
\hline Egypt & 78.0 & 69.0 & 31.2 & 38.7 \\
\hline Emirates & 1045.5 & 75.1 & 9.0 & 10.5 \\
\hline Iran & 198.0 & 70.7 & 24.8 & 30.0 \\
\hline Iraq & 80.9 & 70.0 & 34.0 & 42.2 \\
\hline Kuwait & 865.0 & 73.6 & 10.7 & 12.4 \\
\hline Lebanon & 481.6 & 75.9 & 14.4 & 16.8 \\
\hline Libya & 248.2 & 72.8 & 21.5 & 25.0 \\
\hline Morocco & 96.5 & 68.7 & 38.4 & 45.5 \\
\hline Oman & 341.3 & 73.5 & 13.6 & 15.9 \\
\hline Pakistan & 19.6 & 64.6 & 83.1 & 105.7 \\
\hline Qatar & 1161.1 & 77.2 & 9.6 & 11.2 \\
\hline Saudi Arabia & 436.3 & 73.3 & 15.8 & 18.6 \\
\hline Syrian & 69.0 & 73.9 & 18.0 & 21.2 \\
\hline Tunisia & 172.1 & 73.2 & 22.0 & 26.3 \\
\hline Yemen & 43.6 & 61.1 & 63.1 & 86.1 \\
\hline
\end{tabular}


Mohammad Ahmadi A, et al. Health Spending and Public Health Outcome in Countries of the WHO's EMRO

Table 2. Average performance of health systems in EMR countries during 1995-2011

\begin{tabular}{|c|c|c|c|c|c|c|}
\hline Country & LE & $\begin{array}{l}\text { Saved Infants } \\
\text { from Premature } \\
\text { death }\end{array}$ & $\begin{array}{l}\text { Saved under } 5 \text { years } \\
\text { old child from } \\
\text { Premature death }\end{array}$ & $\begin{array}{c}\text { How much per } \\
\text { capita Dollar Paid } \\
\text { to achieve } 1 \text { Year } \\
\text { LE? }\end{array}$ & $\begin{array}{l}\text { How much Per capita } \\
\text { Dollar Paid to Save } 1 \\
\text { Infant from Premature } \\
\text { death? }\end{array}$ & $\begin{array}{c}\text { How Much Per capita Dollar Paid } \\
\text { to Save } 1 \text { Under } 5 \text { Years Old Child } \\
\text { from Premature death? }\end{array}$ \\
\hline Bahrain & 75.1 & 989.3 & 987.6 & 8.21 & 0.624 & 0.625 \\
\hline Djibouti & 58.0 & 920.1 & 898.9 & 1.01 & 0.064 & 0.065 \\
\hline Egypt & 69.0 & 968.8 & 961.3 & 1.13 & 0.081 & 0.081 \\
\hline Emirates & 75.1 & 991 & 989.5 & 13.92 & 1.055 & 1.057 \\
\hline Iran & 70.7 & 975.2 & 970 & 2.80 & 0.203 & 0.204 \\
\hline Iraq & 70.0 & 966 & 957.8 & 1.16 & 0.084 & 0.084 \\
\hline Jordan & 72.3 & 978.6 & 974.6 & 3.09 & 0.228 & 0.229 \\
\hline Kuwait & 73.6 & 989.3 & 987.6 & 11.75 & 0.874 & 0.876 \\
\hline Libya & 72.8 & 978.5 & 975 & 3.41 & 0.254 & 0.255 \\
\hline Morocco & 68.7 & 961.6 & 954.5 & 1.40 & 0.100 & 0.101 \\
\hline Oman & 73.5 & 986.4 & 984.1 & 4.64 & 0.346 & 0.347 \\
\hline Pakistan & 64.6 & 916.9 & 894.3 & 0.30 & 0.021 & 0.022 \\
\hline Qatar & 77.2 & 990.4 & 988.8 & 15.04 & 1.172 & 1.174 \\
\hline Saudi & 73.3 & 984.2 & 981.4 & 5.95 & 0.443 & 0.445 \\
\hline Sudan & 59.1 & 937.2 & 902.9 & 0.69 & 0.044 & 0.045 \\
\hline Syrian & 73.9 & 982 & 978.8 & 0.93 & 0.070 & 0.070 \\
\hline Tunisia & 73.2 & 978 & 973.7 & 2.35 & 0.176 & 0.177 \\
\hline Yemen & 61.1 & 936.9 & 913.9 & 0.71 & 0.047 & 0.048 \\
\hline
\end{tabular}

According to Table 1, countries with highest levels of average per capita health spending (more than 600 USD) including Qatar, Emirate, Kuwait and Bahrain have the highest average levels of public health outcomes too (more than $75 \mathrm{LE}$ and less than $11 \mathrm{IMR}$ ).Also, countries with the lowest average levels of per capita health spending (less than 60 USD) including Pakistan, Sudan, Yemen and Djibouti have the lowest levels of average public health outcomes(less than $65 \mathrm{LE}$ and more than $60 \mathrm{IMR}$ ).

Table 2 showed average performance of health systems in the WHO Eastern Mediterranean countries during 19952011. This table showed the link between health spending and health outcomes achieved by each country. According to Table 2, countries with better public health status (like:
Qatar, Emirate, Kuwait, Bahrain, Kuwait and Lebanon) need to pay much more than countries with poor public health status (like: Pakistan, Sudan, Yemen and Djibouti) in order to achieve 1 year life expectancy or to save 1 infant or child from premature death.

Diagram 1 showed the per capita dollar paid to achieve 1 year LE by each EMR countries during 1995-2011. Also the Per capita dollar paid to save 1 infant and child from premature death have been showed in Diagram 2 and Diagram 3 respectively. According to the diagrams 1-3, Arab States of the Persian Gulf with top level of health status including Qatar, Emirate, Kuwait, Bahrain and Kuwait, paid much more than the other countries to achieve 1 year life expectancy or to save 1 infant or child from premature death.

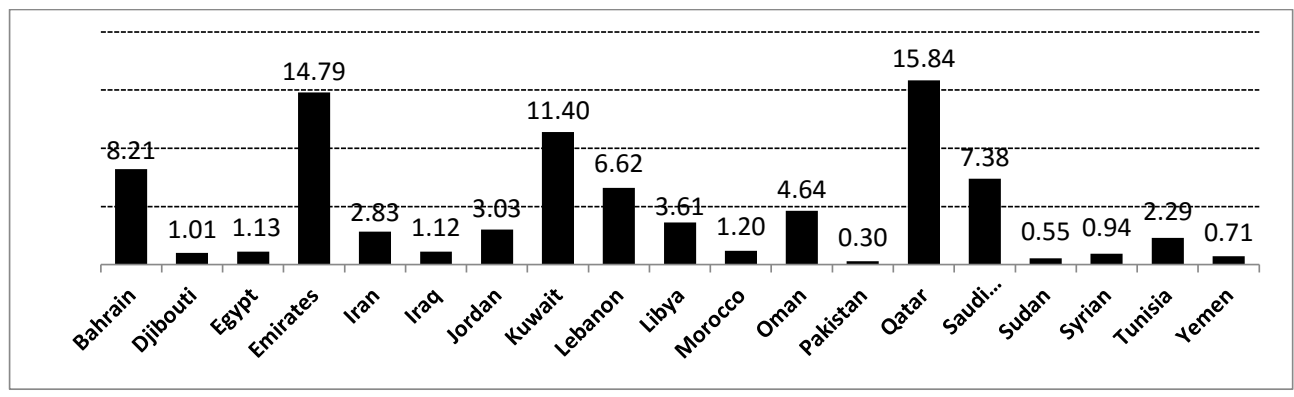

Diagram 1. Per capita dollar paid to achieve 1 year LE by each EMR countries during 1995-2011

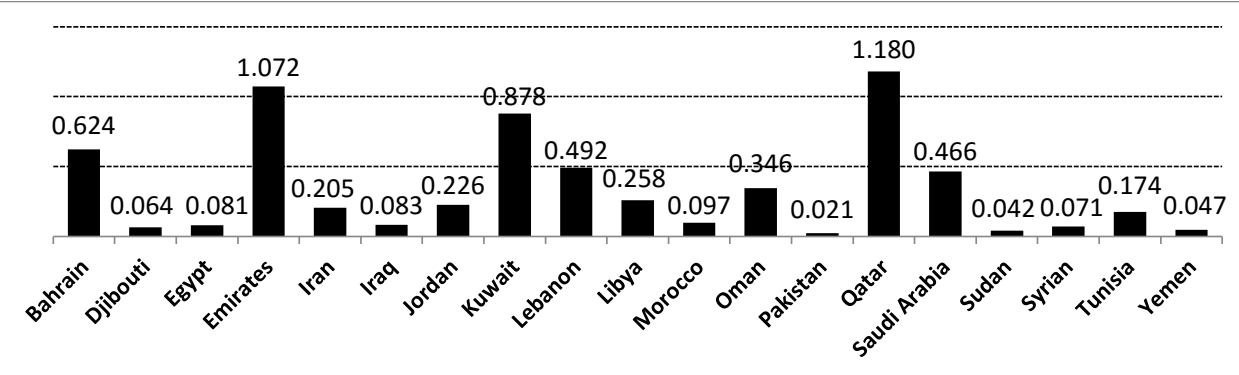

Diagram 2. Per capita dollar paid to save 1 infant from premature death by each EMR countries during 1995-2011 


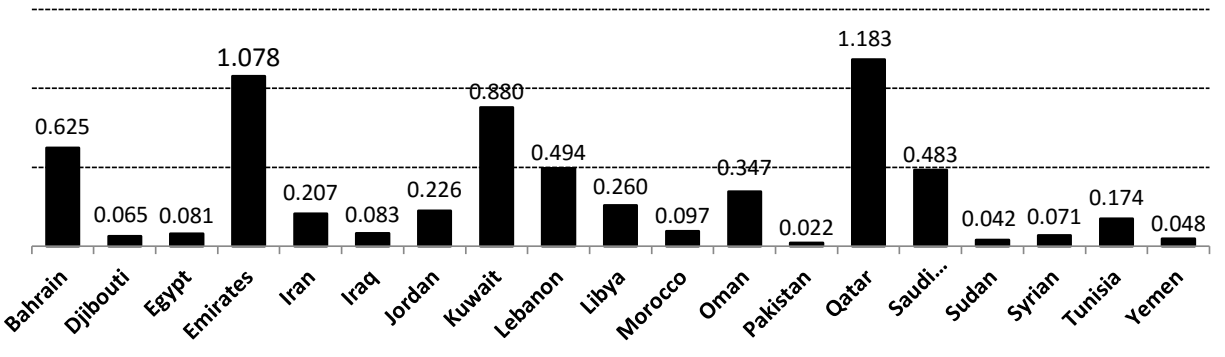

Diagram 3. Per capita dollar paid to save 1 under 5 year's old child by each EMR countries during 1995-2011

\section{Discussion}

Firstly, our findings showed that there is a large gap among countries of the WHO Eastern Mediterranean region in both health spending and public health outcomes. In this region, the minimum spending on health (by Pakistan) was about 60 times less than the maximum spending (by Qatar). The minimum life expectancy was 19 year less than the maximum. Also, the maximum amount of the infant and children mortality rate were 9 and 10 times more than the minimum. It seems that there is an unequal and unbalanced health status among countries in the WHO Eastern Mediterranean Region. Sen and Bonita [19] also discussed about inequality in global health achievement worldwide. They have expressed that a significant worldwide improvement in health status occurred during the past century but the share of this improvement were completely unequal within and between countries that lead to worldwide health inequalities. They called it as "two steps forward and one step back". Health inequalities as a serious trouble has been mentioned with other terms in several studies[15, 20]but an important question is that how can we reduce these inequalities? The last paragraph of the paper is a brief hint and suggestion in this regard.

Secondly, our empirical findings confirm the important effect of health spending on public health outcomes. So, countries with the highest average level of average per capita health spending (more than 600 U.SD) like Qatar, Emirate, Kuwait and Bahrain have the highest average level of public health outcomes too (more than $75 \mathrm{LE}$ and less than 11 IMR). Also countries with the lowest average level of per capita health spending (less than 60 U.SD) like Pakistan, Sudan, Yemen and Djibouti have the lowest level of average public health outcomes too (less than 65 LE and more than 60 IMR). This is while our empirical findings confirm that Syria is one considerable exemption. Among the 19 studied countries, Syria was the $15^{\text {th }}$ country in regards to per capita spending on health (less than 70 U.SD) but is the $4^{\text {th }}$ country in life expectancy achievement and $7^{\text {th }}$ and $8^{\text {th }}$ country with the minimum infant mortality rate and children mortality rate respectively. However, our general findings confirm that higher level of health spending is associated with higher public health outcomes. These results suggest that countries interested in achieving the Millennium Development Goals (MDGs) should consider expanding total public and private health spending as an effective mechanism to decrease infant and child mortality and increase life expectancy. But it should be considered that the health status is not only affected by health spending. Many other factors which are contributed to public health outcomes of a country, including "biology, environment, lifestyles, and the health care system". Surveying the literature on the link between health expenditures and outcomes confirms the findings of our study about the relation between health spending and public health outcomes. A study conducted by Kim and Lane [21] in 2013 empirically analyzed the relationship between public health expenditure and national health outcomes among 17 OECD countries. The findings showed that the government health expenditure (as public health spending) has positive and negative effects on life expectancy and infant mortality rate. So it is suggested that higher public health spending can lead to a better overall health status for individuals. A same study in Nigeria also showed that public health expenditure has a negative effect on infant mortality and under-5 mortalities [22]. Novignon et al. [7] in a study which was conducted in 2012, assessed the effects of public and private health care expenditure on health status in the SubSaharan Africa region. Their study also showed that both the public and private health spending can positively lead to a better health status through improving life expectancy at birth, reducing death and infant mortality rate but public health care spending had relatively higher impact. Also another study conducted by Gani[23] in the Pacific Island countries provides strong evidence that per capita health expenditure is an important factor in determining health outcomes measured by infant and under five mortality rate and crude death rate. Surveying the literature implies the fact that health care expenditure remains a crucial component of health status improvement in both developed and developing countries. So increasing health care expenditure can be a significant step in achieving the Millennium Development Goals. But can increasing health spending in all countries improve health status in the same size? This question has been discussed below.

Thirdly, our empirical findings confirm the decreasing return to scale of investment in health among studied countries. So countries with better public health status like (Qatar, Emirate, Kuwait, Bahrain, Kuwait and Lebanon) need to pay much more money than countries with poor public health status (Pakistan, Sudan, Yemen and Djibouti) to increase 1 year life expectancy or to save 1 more infant or child from premature death. These can be due to the fact that decreasing the infant mortality rate or increasing life expectancy in countries with poor health status is possible through less expensive health activities like vaccination but in countries with better health status it's possible only through more expensive treatment activities like establishing Neonatal Intensive Care Units (NICU). According to these results we can say that the allocation of international aids and loans to finance healthcare in countries with poor public health status can be an effective way to promoting and converging health status and decreasing health inequalities among countries. Achieving a more positive health results in poor health countries is possible through simple health activities with less spending. 
Finally, we should explain some points and limitations. Firstly, it should be emphasized that health spending is only one of the most important contributors for improving health status, so it is not completely true that by only increasing per capita, health spending countries can improve health outcomes. Social and political determinants of health and performance of health systems play a significant role in the reduction of mortality and improved health outcomes. So it should be reemphasized that health spending is one of the most important contributors (not all), but there are several other contributors. Secondly, although allocation of international aids and loans to poor health countries can be an effective way to decrease health inequalities but it should also be considered that the ODA (Official Development Aids) are not sufficient enough to completely eliminate the health inequalities worldwide. Also, in most countries it's only a small component of total health expenditures. So still more studies needs to find and suggest ways to reduce health inequalities worldwide.

\section{Conclusion}

There is unequal health status among countries in the WHO Eastern Mediterranean region. On the other hand, our empirical findings confirm that more health spending is associated with better health status and health spending has a decreasing return to scale among studied countries. So, achieving a more positive health results in poor health countries is possible through simple health activities with less spending (like vaccination). The policy implication is that the allocation of international financial aids, donor grants and loans to finance cost-effective health programs in such countries can be one effective way to reduce the health inequality in the region and to converge health status and more equal achievements to the Millennium Development Goals (MDGs) in the region.

\section{Acknowledgments}

We would like to thank all those who helped us in order to prepare this paper.

\section{Authors' Contributions}

All the authors were involved in every stage of this study. Also, all the authors confirmed the final draft before submission.

\section{Financial Disclosure}

The authors declared no financial disclosure.

\section{Funding/Support}

No funding support.

\section{References}

1. Bokhari FA, Gai Y, Gottret P. Government health expenditures and health outcomes. Health Econ. 2007;16(3):257-73.

2. Lozano R, Wang H, Foreman KJ, Rajaratnam JK, Naghavi M, Marcus JR, et al. Progress towards Millennium Development Goals 4 and 5 on maternal and child mortality: an updated systematic analysis. Lancet. 2011;378(9797):1139-65.

3. Rasooly MH, Govindasamy P, Aqil A, Rutstein S, Arnold F, Noormal B, et al. Success in reducing maternal and child mortality in Afghanistan. Glob Public Health. 2014;9(sup1):29-42.

4. Tang KC, Ståhl T, Bettcher D, De Leeuw E. The Eighth Global Conference on Health Promotion: health in all policies: from rhetoric to action. Health Promot Int. 2014;29(suppl 1):11-8.

5. Murray CJ, Laakso T, Shibuya K, Hill K, Lopez AD. Can we achieve Millennium Development Goal 4? New analysis of country trends and forecasts of under-5 mortality to 2015 . Lancet. 2007;370(9592):1040-54.

6. Mays GP, Smith SA. Evidence links increases in public health spending to declines in preventable deaths. Health Affairs. 2011;30(8):1585-93.

7. Novignon J, Olakojo SA, Nonvignon J. The effects of public and private health care expenditure on health status in sub-Saharan Africa: new evidence from panel data analysis. Health Econ Rev. 2012;2(1):1-8.

8. Rajkumar AS, Swaroop V. Public spending and outcomes: Does governance matter? J Dev Econ. 2008;86(1):96-111.

9. Joumard I, André C, Nicq C. Health care systems: efficiency and institutions. 2010.

10. Lavado RF, Graves CM, Haakenstad A, Bui AL, Brooks BP, Shoemaker B, et al. A systematic analysis of national health accounts from 1990 to 2010. Lancet. 2013;381:S80.

11. Poullier J-P. Patterns of global health expenditures: results for 191 countries. World Health Organization; 2002.

12. Organization WH. Regional Health Systems Observatory-EMRO. World Health Organization. 2011.

13. Alwan A. Addressing health challenges in the five regional priority areas: progress in one year. EMHJ. 2014;20(10).

14. Meskarpour-Amiri M, Mehdizadeh P, Barouni M, Dopeykar N, Ramezanian M. Assessment the trend of inequality in the distribution of intensive care beds in Iran: using GINI index. Glob J Health Scie. 2014;6(6):28-35.

15. Kruk ME, Freedman LP. Assessing health system performance in developing countries: a review of the literature. Health Policy. 2008;85(3):263-76.

16. Mays GP, McHugh MC, Shim K, Perry N, Lenaway D, Halverson $\mathrm{PK}$, et al. Institutional and economic determinants of public health system performance. Am J Public Health. 2006;96(3):523-31.

17. Day KM, Tousignant J. Health Spending, Health Outcomes, and Per Capita Income in Canada: A Dynamic Analysis: Department of Finance, Economic and Fiscal Policy Branch; 2005.

18. Anyanwu JC, Erhijakpor AE. Health expenditures and health outcomes in Africa. Afr Dev Rev. 2009;21(2):400-33.

19. Sen K, Bonita R. Global health status: two steps forward, one step back. Lancet. 2000;356(9229):577-82.

20. Baschieri A. Health inequities in the Eastern Mediterranean Region: selected country case studies. 2014.

21. Kim TK, Lane SR. Government health expenditure and public health outcomes: a comparative study among 17 countries and implications for US health care reform. Am Int J Contemp Res. 2013;3(9):8-13.

22. Yaqub J, Ojapinwa T, Yussuff R. Public health expenditure and health outcome in nigeria: the impact of governance. Eur Scie J. 2012;8(13)

23. Gani A. Health care financing and health outcomes in Pacific Island countries. Health Policy Plan. 2009;24(1):72-81. 